\title{
Schwann Cells Transplantation Improves Locomotor Recovery in Rat Models with Spinal Cord Injury: a Systematic Review and Meta-Analysis
}

\author{
Lei Yang ${ }^{a}$ Yingbin Ge ${ }^{b}$ Jian Tang ${ }^{a}$ Jinxia Yuan ${ }^{d}$ Dawei Ge ${ }^{a}$ Hongtao Chen ${ }^{a}$ \\ Hongxiu Zhang ${ }^{c}$ Xiaojian $\mathrm{CaO}^{\mathrm{a}}$ \\ aDepartment of Orthopedics, the First Affiliated Hospital of Nanjing Medical University, Nanjing, \\ bDepartment of Physiology, Nanjing Medical University, Nanjing, 'Department of Obstetrics and \\ Gynecology, the First Affiliated Hospital of Nanjing Medical University, Nanjing, dDepartment of \\ Cardiology, The 81st Hospital of PLA, Nanjing, Jiangsu, China
}

\section{Kew Words}

Spinal cord injury $\bullet$ Locomotor recovery $\bullet$ BBB score $\bullet$ Schwann cells $\bullet$ Meta-analysis

\begin{abstract}
Background/Aims: Schwann cells (SCs) which were demonstrated to be responsible for axonal myelination and ensheathing are widely studied and commonly used for cell transplantation to treat spinal cord injury (SCI). We performed this meta-analysis to summarize the effects of SCs versus controls for locomotor recovery in rat models of traumatic SCI. Methods: Studies of the BBB scores after transplantation of SCs were searched out from Pubmed, Cochrane Library, Medline databases and analyzed by Review Manager 5.2.5. Results: Thirteen randomized controlled animal trials were selected with 283 rats enrolled. The studies were divided to different subgroups by different models of SCI, different cell doses for transplantation, different sources of SCs and different transplantation ways. The pooled results of this meta-analysis suggested that SCs transplantation cannot significantly improve the locomotor recovery at a short time after intervention ( 1 week after transplantation) in both impacted and hemisected SCI models. However, at a longer time after intervention (3, 5-7 and over 8 weeks after transplantation), significant improvement of BBB score emerged in SCs groups compared with control groups. Subgroup analyses revealed that SCs transplantation can significantly promote locomotor recovery regardless of in high or low doses of cells, from different sources (isolated from sciatic nerves or differentiated from bone marrow stromal cells(BMSCs)) and with or without scaffolding. Conclusion: SCs seem to demonstrate substantial beneficial effects on locomotor recovery in a widely-used animal models of SCI.
\end{abstract}




\section{Cellular Physiology Cell Physiol Biochem 2015;37:2171-2182 \begin{tabular}{l|l|l|l}
\cline { 2 - 2 } DOI: 10.1159/000438574 & ( ) 2015 The Author(s). Published by S. Karger AG, Basel
\end{tabular} and Biochemistry Published online: November 26, 2015 www.karger.com/cpb}

Yang et al.: Schwann Cells Transplantation in Spinal Cord Injury

\section{Introduction}

Spinal cord injury (SCI) is a common traumatic disorder which affects thousands of individuals yearly and usually leads to devastating neurological deficits and disabilities [1-3]. Due to the loss of sensory and motor capabilities, patients are usually present with paraplegia or tetraplegia. Besides, other relative problems such as bladder dysfunction, bowel problems, and cardiac and respiratory dysfunctions seem to be the most deadly threat $[3,4]$. Given all this, it is really urgent to develop effective therapeutic strategies to target this problem.

Though current treatments, including high dose of methylprednisolone [5], surgical interventions to stabilize and decompress the spinal cord $[6,7]$ and rehabilitation training [8], have a certain improving effect, there is yet no cure for SCI to date. In recent years, approaches of cell transplantation have been widely investigated to address various kinds of disorders, SCI included [9-11]. Below are several types of cells which are commonly used for cell transplantation in SCI models: neural stem cells(NSCs),mesenchymal stem cells (MSCs), Schwann cells(SCs), embryonic stem (ES)cells, olfactory ensheathing cells (OECs), activated macrophages, and more recently, induced pluripotent stem (iPS) cells, etc. [3, 9]. Among them, Schwann cells, glial cells of peripheral nervous system (PNS), play a significant role in promoting axonal regeneration after PNS injury. This effect may be related to their intrinsic characteristics or the ability to secrete a variety of neurotrophic factors [12-17]. Various studies have demonstrated this regenerative potential of Schwann cells in animal models with SCI. However there are still some investigators who questioned its efficacy of SCs transplantation in treating SCI $[15,18]$.

Meta-analyses of controlled studies increase the power and precision of the estimated intervention effect and therefore yield a more powerful test of the null hypothesis than any of the separate studies [19]. To our knowledge, no quantitative data to date was available about synthesis of SCs transplantation therapy for SCI. We therefore conducted this systematic review and meta-analysis to investigate locomotor recovery of SCs transplantation for SCI through the comparison between the SCs group and the control group.

\section{Materials and Methods}

\section{Search strategy}

Electronic databases included PubMed, Cochrane Library and Medline were searched to retrieve related studies with the Medical Subject Heading (MeSH) keywords "Schwann cells", "transplantation" and "spinal cord injury". No language, publication date, or publication status restrictions were imposed. Titles and abstracts of identified references were screened for eligibility and clearly irrelevant references were excluded.

Inclusion criteria

Types of studies. Randomized controlled studies assessing the administration of SCs to rats with traumatic SCI.

Types of participants. Laboratory rats of any age, gender or strain exposed to traumatic SCI induced by contusion, compression, hemisection or transection.

Types of intervention. SCs irrespective of donor species or tissue origin (isolated from sciatic nerves, differentiated from BMSCs, etc.) were all included. Labeling or transfection with markers for cellular tracing and imaging (green fluorescent protein, lacZ, etc.) were also included. The included reference contained at least two groups: SCs transplantation group and Control group. Control interventions consisted of placebo (saline, culture medium or similar vehicle) or no treatment.

Type of outcome measure. Locomotor recovery of the rats were assessed by the Basso-Beattie-Bresnahan (BBB) locomotor rating scale ranging from 0 (no observable hindlimb movement) to 21 (coordinated gait, consistent toe clearance, predominant paw position is parallel throughout stance, consistent trunk stability, 


\section{Cellular Physiology Cell Physiol Biochem 2015;37:2171-2182 \begin{tabular}{ll|l}
\hline DOI: 10.1159/000438574 & ( ) 2015 The Author(s). Published by S. Karger AG, Basel
\end{tabular} and Biochemistry Published online: November 26, 2015 www.karger.com/cpb}

Yang et al.: Schwann Cells Transplantation in Spinal Cord Injury

and tail is consistently up). It is a useful indicator of the basic overground locomotion and can be used to evaluate limb movements and walking characteristics in an open-field environment [20,21].

\section{Exclusion criteria}

Articles meeting one of the following criteria were excluded: No access to the full text; no access to means and standard deviations of the BBB scores; Co-culture or concomitant injection with other cell types or use of adjuvant products (except use of scaffolding during transplantation); trials of low quality; review.

\section{Selection of studies}

Two investigators independently screened titles, abstracts and full texts of the relevant references based on the same selection criteria. Studies beyond the inclusion criteria were excluded. Any disagreement was resolved through discussion. A third author was consulted if disagreement persisted.

\section{Data extraction}

The data was extracted independently by two reviewers and was rechecked after the extraction through reading the titles, abstracts and the full text if necessary according to the inclusion and exclusion criteria. Details included first author's name, publication year, number of animals in each group, spinal cord injury level, method used to induce SCI, cell count for transplantation, cell transplantation time, with or without scaffold and measured outcomes. For each comparison, data was collected for mean outcome, standard deviation (SD) and the number of animals per group. In studies with multiple intervention arms, only data from the SCs transplantation group and control group were considered in this analysis. If any data were not indicated in the text but only shown in graphs, data were estimated using GetData Graph Digitizer 2.24). Any disagreement regarding eligibility during the extraction was discussed and resolved.

\section{Assessment of methodology quality}

Assessment of the quality of the included studies was performed according to the following 6 items (Cochrane Handbook for Systematic Reviews of Interventions version 5.1.0).

A: random sequence generation;

B: allocation concealment;

C: blinding of outcome assessment;

D: incomplete outcome data;

E: selective reporting;

F: other bias.

Every study was assessed by 2 independent researchers and the judgment of every item was low risk, unclear or high risk. Any disagreement regarding eligibility during the extraction was discussed and resolved.

\section{Statistical analysis}

The Review Manager Software package (version 5.2.5; the Cochrane collaboration) was used to conduct this meta-analysis. For continuous variables, the weighted mean difference (WMD) were measured with the 95\% CIs. WMDs were considered statistically significant at the $\mathrm{P}<0.05$ level. $\mathrm{X}^{2}$ and $\mathrm{I}^{2}$ tests were adopted to evaluate the statistical heterogeneity among studies and subgroups. Both a fixed-effects (FE) model and a random-effects (RE) model were used to obtain summary WMDs. The FE model was employed with the absence of heterogeneity, otherwise the RE model was employed. Begg's funnel plot and Egger's test were performed to assess the publication bias using the software Stata 12.0 (StataCorp LP, College Station, TX, USA). Subgroup analyses were performed with stratification according to several pre-specified categorical explanatory variables. The following are detailed standards for grouping:

Different types of SCI models: Impacted models (set up with weight-drop, including Allen's weightdropping model, improved Allen's weight-dropping model, NYU Impactor model .etc.) hemisected models and transected models $[3,20]$. Different doses of cells for transplantation: cells count for injection $<1 * 10^{6}$ and $\geq 1 * 10^{6}$. Different sources of Schwann cells: isolated from sciatic nerves of rats and differentiated from BMSCs. Cell transplantation with or without scaffolding. 


\section{Cellular Physiology Cell Physiol Biochem 2015;37:2171-2182 \begin{tabular}{ll|l} 
DOI: 10.1159/000438574 & $\begin{array}{l}\text { ( ) 2015 The Author(s). Published by S. Karger AG, Basel } \\
\text { www.karger.com/cpb }\end{array}$
\end{tabular}}

Yang et al.: Schwann Cells Transplantation in Spinal Cord Injury

\section{Results}

\section{Selection of studies}

We initially identified 156 eligible studies to be included in our main meta-analysis. Through reading the titles, abstracts and the full texts, 143 studies were excluded from further analyses. Finally a total of 13 studies [22-34] published from 2007 to 2015 were included in this meta-analysis. The detailed process followed for article selection is shown in Fig. 1.

Characteristics of the studies included in the meta-analysis

Characteristics of the included studies were shown in Table 1, including the following items. Ways to induce SCI: SCI contusion models of rats were induced by the impactor in 10 studies, by hemisection in 1 study and by transection in 2studies. Levels of SCI: All studies reported induction of SCI in the thoracic region with spinal cord levels T8 to T10. No study investigated a cervical SCI model. Doses of cells for transplantation: Rats in experimental groups received injection of Schwann cells in a higher dose of $\geq 1^{*} 10^{6}$ in 7 studies and in a lower dose of $<1^{*} 10^{6}$ in 5 studies. Cell dose for injection was not mentioned in 1 study. Intervention time: Time from SCI to intervention was 6 hours in 1 study and 1 week in 10 studies. In another 2 studies, cell transplantation was performed immediately after the injury. Sources of Schwann cells: Most of the included studies, except for 2 (in which Schwann cells were obtained through differentiation from BMSCs), employed Schwann cells isolated from sciatic nerves of rats for transplantation.

Table 1. Characteristics of included studies. SN: sciatic nerves of rats; DB: Differentiated from BMSC

\begin{tabular}{|c|c|c|c|c|c|c|}
\hline Author and Year & Type of SCI & $\begin{array}{l}\text { Level of } \\
\text { injury }\end{array}$ & $\begin{array}{l}\text { Cells } \\
\text { count }\end{array}$ & $\begin{array}{l}\text { Time from injury to } \\
\text { transplantation }\end{array}$ & $\begin{array}{c}\text { Sources of } \\
\text { Schwann cells }\end{array}$ & Scaffolding \\
\hline \multicolumn{7}{|l|}{$\begin{array}{c}\text { Shu-quan Zhang } \\
2015\end{array}$} \\
\hline & Impacted & T9 & $1 \times 10^{\wedge} 7$ & 6 hours & SN & No \\
\hline \multicolumn{7}{|l|}{$\begin{array}{c}\text { Wiesław Marcol } \\
2015\end{array}$} \\
\hline & Impacted & $\mathrm{T} 10$ & $3 \times 10^{\wedge} 5$ & $1 w$ & SN & No \\
\hline \multicolumn{7}{|l|}{$\begin{array}{c}\text { Xiaofei Wang } \\
2014\end{array}$} \\
\hline \multirow{2}{*}{ Haruo Kann 2014} & Impacted & T9 & $1 \times 10^{\wedge} 6$ & $1 w$ & SN & No \\
\hline & Impacted & T8 & $2 \times 10^{\wedge} 6$ & $1 w$ & SN & No \\
\hline \multirow{2}{*}{$\begin{array}{l}\text { Arash Zaminy } \\
2013\end{array}$} & & & & immediately after & & \\
\hline & \multicolumn{6}{|c|}{$\begin{array}{c}\text { Caitlin E. Hill } \\
2012\end{array}$} \\
\hline \multirow[b]{2}{*}{$\begin{array}{l}\text { Haibao Wang } \\
2012\end{array}$} & Impacted & T9 & $2 \times 10^{\wedge} 6$ & $1 w$ & SN & No \\
\hline & transected & $?$ & ? & $\begin{array}{l}\text { immediately after } \\
\text { injury }\end{array}$ & SN & No \\
\hline \multicolumn{7}{|l|}{$\begin{array}{l}\text { Pourheydar B } \\
2011\end{array}$} \\
\hline \multicolumn{7}{|l|}{$\begin{array}{c}\text { Takahito Kamada } \\
2011\end{array}$} \\
\hline $\begin{array}{c}\text { Kelli G. Sharp } \\
2010\end{array}$ & Impacted & T9 & $2 \times 10^{\wedge} 6$ & $1 w$ & DB & Yes \\
\hline $\begin{array}{c}\text { YUKIOSOMEYA } \\
2008\end{array}$ & Impacted & T8/9 & $2 \times 10^{\wedge} 6$ & $1 w$ & SN & No \\
\hline XUEBAO ZHANG & Impacted & T8/9 & $5 \times 10^{\wedge} 5$ & $1 w$ & SN & No \\
\hline 2007 & $\begin{array}{l}\text { Completely } \\
\text { transected }\end{array}$ & $\mathrm{T} 10$ & $1 \times 10^{\wedge} 6$ & $1 w$ & $\mathrm{SN}$ & No \\
\hline
\end{tabular}




\section{Cellular Physiology Cell Physiol Biochem 2015;37:2171-2182 \begin{tabular}{l|l} 
DOI: 10.1159/000438574 & ( ) 2015 The Author(s). Published by S. Karger AG, Basel
\end{tabular}

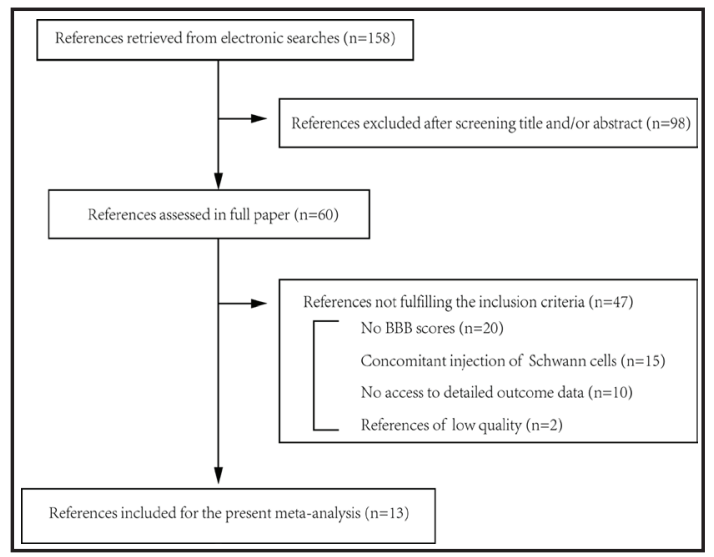

Fig. 1. Flow chart illustrating the literature search strategy and the different phases of study eligibility assessment.

Methodological study quality assessment A summary of methodological domain assessment for each study is detailed in Fig. 2. Only 5 studies mentioned the blinding of outcome assessment clearly. Overall, the risk of bias was considered as a low level.

\section{BBB score in subgroups of different types of SCI models}

BBBscore at 1 week aftertransplantation. There was no significant difference between the SCs groups and control groups in the BBB score of both impacted and hemi-sectioned injury models subgroups at 1 week after SCs transplantation. The heterogeneity was high in the impacted model subgroup $\left(I^{2}=93 \%\right)$. The BBB score was significantly increased in the SCs group than the control group in the transected injury model subgroup (WMD $=1.83 ; 95 \%$ CI, 1.57-2.09; $\mathrm{P}<0.00001)$. No significant difference was found between the two groups in the overall BBB score at 1 week after SCs transplantation (WMD $=0.82 ; 95 \%$ CI: $-0.02-1.67 ; \mathrm{P}=0.06)$. The total heterogeneity was high $\left(\mathrm{I}^{2}=96 \%\right)$. The heterogeneity between subgroups was high $\left(I^{2}=98.2 \%\right)$ (Fig. 3a).

$B B B$ score at 3 weeks after transplantation. The BBB score of impacted injury model subgroup was significantly increased in the SCs group than the control group at 3 weeks after $\mathrm{SCs}$ transplantation (WMD $=1.22 ; 95 \% \mathrm{CI}$ : $0.37-2.07 ; \mathrm{P}=0.005)$. The heterogeneity was high $\left(\mathrm{I}^{2}=95 \%\right)$. The BBB score of completely transected injury model subgroup was significantly increased in the SCs group than the control group at 3 weeks after SCs transplantation $(\mathrm{WMD}=1.94 ; 95 \%$ CI: 0.25-3.63; $\mathrm{P}=0.02)$. The heterogeneity was high $\left(\mathrm{I}^{2}=89 \%\right)$. In the hemi-sectioned injury model subgroup, SCs transplantation also improved the outcome of BBB score compared with the control group (WMD $=2.40 ; 95 \%$ CI: 1.92-2.88; P < 0.00001). The overall BBB score was significantly increased in the SCs group than the control group at 3 weeks after SCs transplantation (WMD $=1.49 ; 95 \%$ CI: $0.62-2.35 ; \mathrm{P}=0.0008$ ). The total heterogeneity was high $\left(I^{2}=97 \%\right)$. The heterogeneity between subgroups was medium $\left(I^{2}=\right.$ 64.6\%) (Fig. 3b).

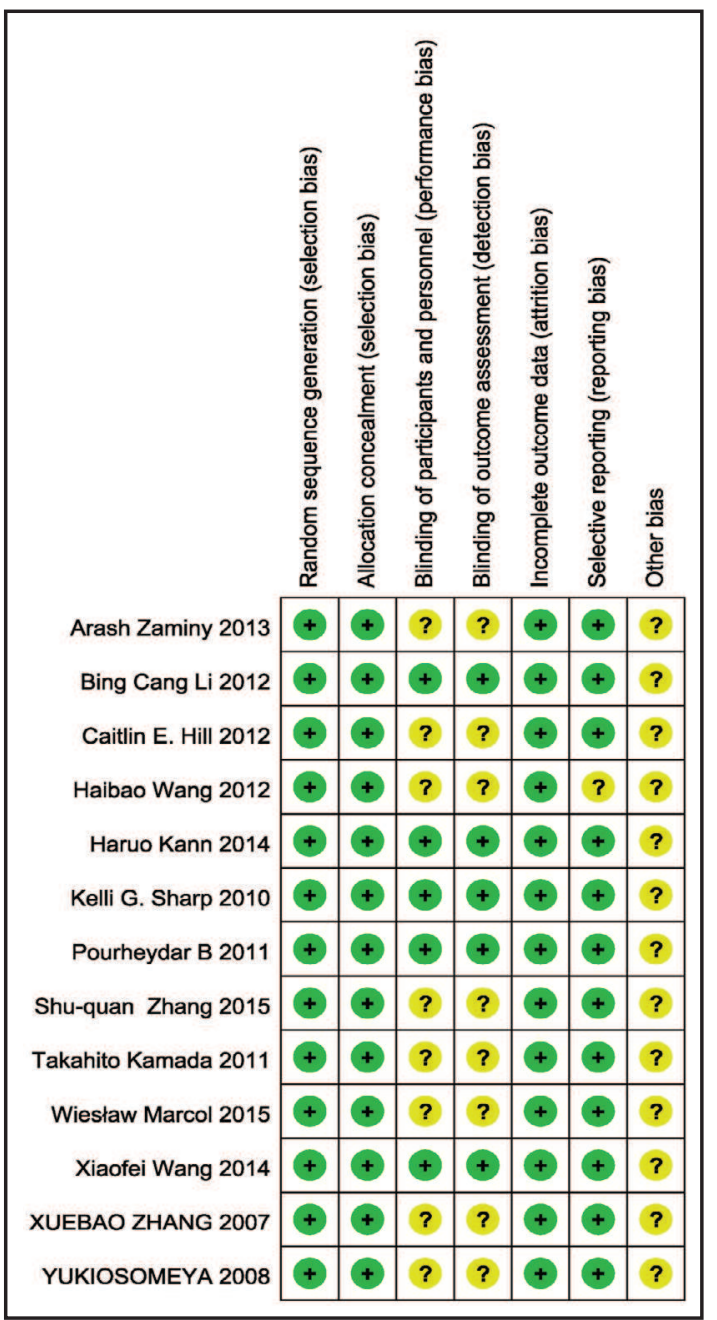

Fig. 2. Assessment of the quality of the included studies: A review of the author's judgments about each risk of bias item for each included study. + is 'low risk', - is 'high risk' ? is 'unclear'. 

Cellular Physiology Cell Physiol Biochem 2015;37:2171-2182

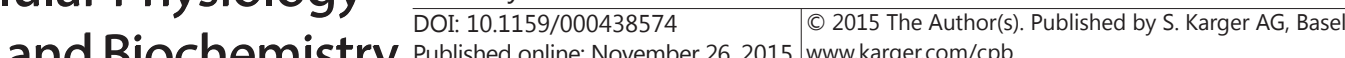 and Biochemistry Published online: November 26, 2015 www.karger.com/cpb

Fig. 3. Forest plots of the differences in the BBB score of the SCs and control groups in different model subgroups at different time after transplantation. (a) at 1 week after transplantation (b) at 3 weeks after transplantation (c) at 5-7 weeks after transplantation (d) at over 8 weeks after transplantation.

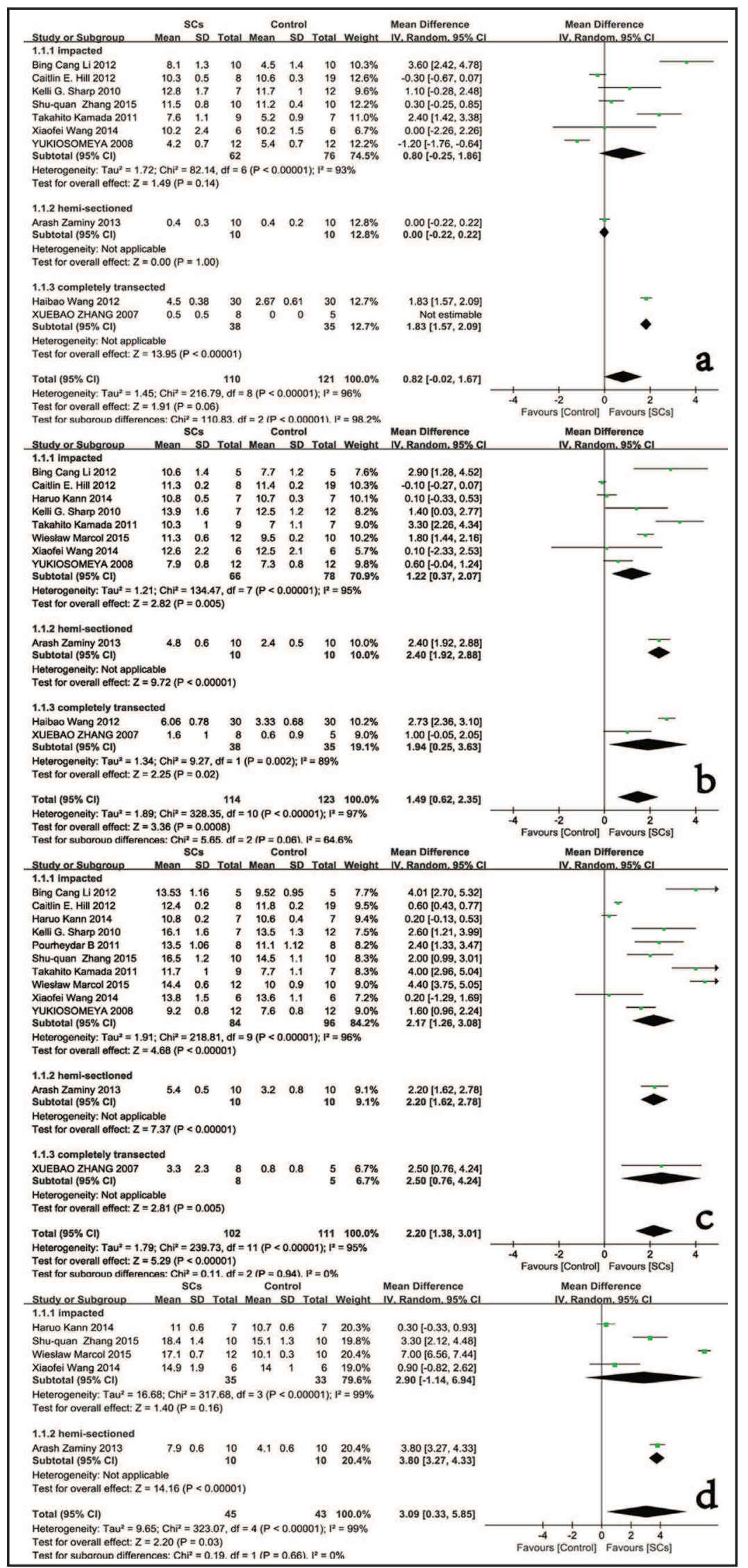




\section{Cellular Physiology \\ Cell Physiol Biochem 2015;37:2171-2182 \begin{tabular}{l|l|l|l|l} 
DOI: 10.1159/000438574 & ( 2015 The Author(s). Published by S. Karger AG, Basel
\end{tabular}

Yang et al.: Schwann Cells Transplantation in Spinal Cord Injury

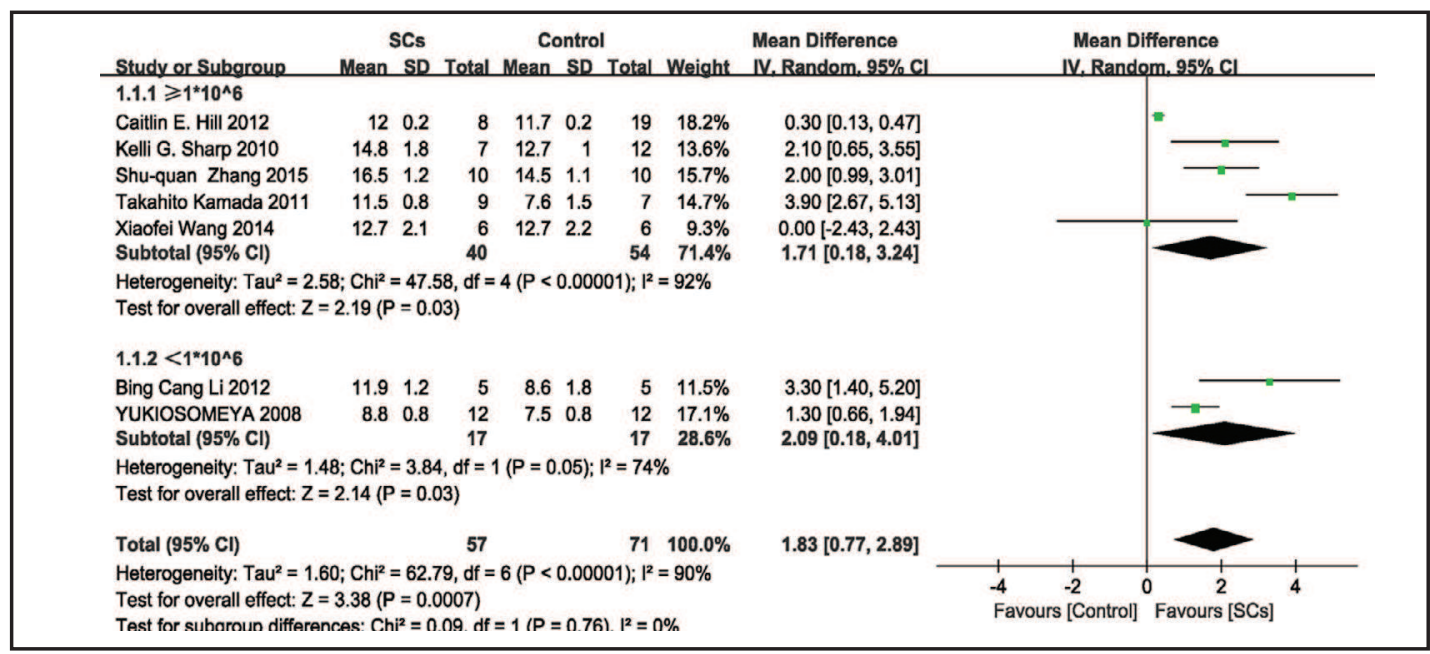

Fig. 4. Forest plot of the differences in the BBB score of the SCs and control groups in subgroups of different cell counts at 4 weeks after transplantation.

BBB score at 5-7 weeks after transplantation. The BBB score of impacted injury model subgroup was significantly increased in the SCs group than the control group at 5-7 weeks after SCs transplantation (WMD $=2.17 ; 95 \% \mathrm{CI}$ : 1.26-3.08; P < 0.00001). The heterogeneity was high $\left(\mathrm{I}^{2}=96 \%\right)$. In the hemi-sectioned injury model subgroup, SCs transplantation improved the outcome of BBB score compared with the control group (WMD $=2.20 ; 95 \% \mathrm{CI}$ : 1.62-2.78; $\mathrm{P}<0.00001)$.

Similarly, in the completely transected injury model subgroup, SCs transplantation improved the outcome of BBB score compared with the control group (WMD $=2.50 ; 95 \%$ CI: 0.76-4.24; $\mathrm{P}=0.005)$. The overall BBB score was significantly increased in the SCs group than the control group at 5-7 weeks after SCs transplantation (WMD $=2.20 ; 95 \% \mathrm{CI}: 1.38-$ 3.01; $\mathrm{P}<0.00001)$. The total heterogeneity was high $\left(\mathrm{I}^{2}=95 \%\right)$.

The heterogeneity between subgroups was low $\left(\mathrm{I}^{2}=0 \%\right)$ (Fig. 3c).

$B B B$ score at over 8 weeks after transplantation. There was no significant difference between the SCs and control groups in the BBB score of impacted injury model subgroup at over 8 weeks after SCs transplantation (WMD = 2.90; 95\% CI: $-1.26-6.94 ; \mathrm{P}=0.16)$. The heterogeneity was high $\left(\mathrm{I}^{2}=99 \%\right)$.

In the hemi-sectioned injury model subgroup, SCs transplantation improved the outcome of BBB score compared with the control group (WMD = 3.80; 95\% CI: 3.27-4.33; $\mathrm{P}<0.00001)$. The overall BBB score was significantly increased in the SCs group than the control group at over 8 weeks after SCs transplantation (WMD = 3.09; 95\% CI: 0.33-5.85; P $=0.03)$. The total heterogeneity was high $\left(I^{2}=99 \%\right)$. The heterogeneity between subgroups was not found $\left(\mathrm{I}^{2}=0 \%\right)$ (Fig. 3d).

BBB score in subgroups of different cell counts for transplantation

Studies were divided into 2 subgroups, one subgroup received SCs transplantation at the cell count of $\geq 1.0^{*} 10^{6}$, the other $<1.0^{*} 10^{6}$. BBB score at 4 weeks after intervention was compared between SCs group and control group in the 2 different subgroups. The BBB score of $\geq 1.0^{*} 10^{6}$ subgroup was significantly increased in the SCs group than the control group at 4 weeks after SCs transplantation (WMD $=1.71 ; 95 \% \mathrm{CI}$ : $0.18-3.24 ; \mathrm{P}=0.03$ ). The heterogeneity was high $\left(I^{2}=92 \%\right)$. Significance was also found between SCs group and the control group in the BBB score of $<1.0^{*} 10^{6}$ subgroup (WMD $=2.09 ; 95 \% \mathrm{CI}$ : $0.18-4.01$; P $=0.03)$. The heterogeneity was medium $\left(I^{2}=74 \%\right)$. The overall BBB score was significantly increased in the SCs group than the control group at 4 weeks after SCs transplantation $(\mathrm{WMD}=1.83 ; 95 \% \mathrm{CI}: 0.77-2.89 ; \mathrm{P}=0.007)$. The total heterogeneity was high $\left(\mathrm{I}^{2}=90 \%\right)$. The heterogeneity between subgroups was not found $\left(\mathrm{I}^{2}=0 \%\right)$ (Fig. 4). 


\section{Cellular Physiology \\ Cell Physiol Biochem 2015;37:2171-2182

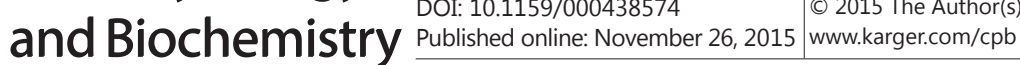

Yang et al.: Schwann Cells Transplantation in Spinal Cord Injury

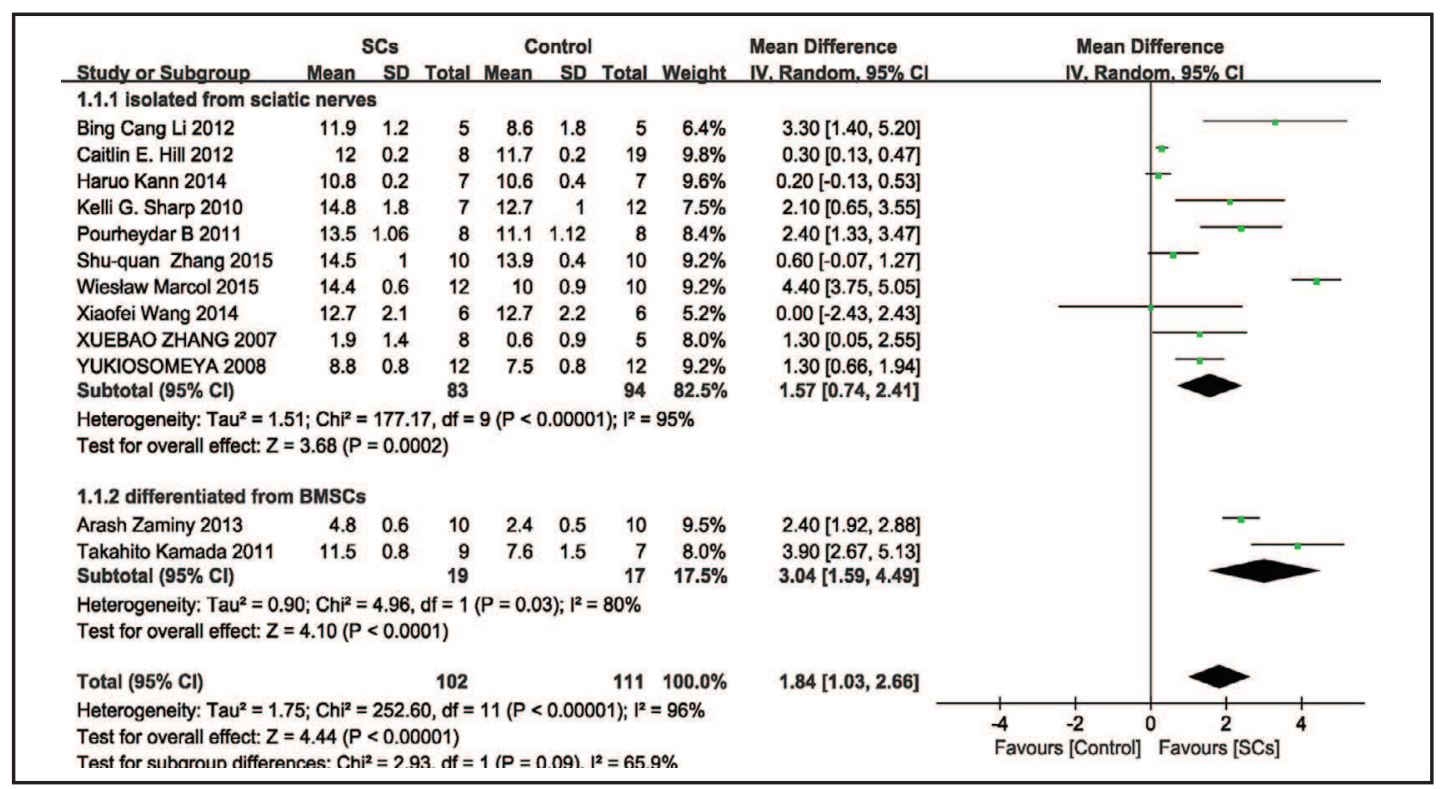

Fig. 5. Forest plot of the differences in the BBB score of the SCs and control groups in subgroups of different cell sources at 4 weeks after transplantation.

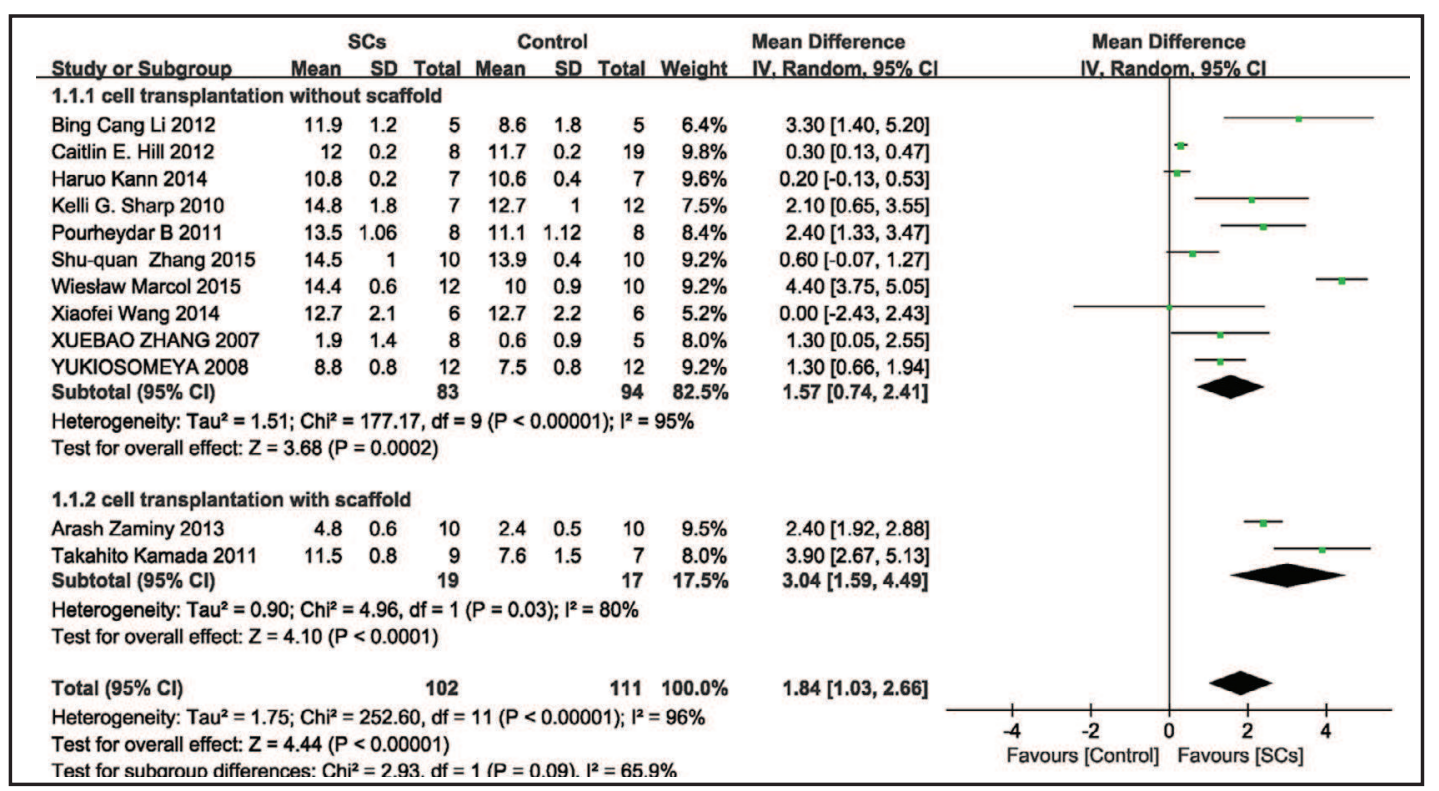

Fig. 6. Forest plot of the differences in the BBB score of the SCs and control groups in subgroups of different transplantation ways at 4 weeks after transplantation.

BBB score in subgroups of different sources of SCs for transplantation

According to different sources of SCs, studies were divided into 2 subgroups, SCs were isolated from sciatic nerves of rats in one subgroup (SN) and differentiated from BMSCs (DB) in the other group. BBB score at 4 weeks after intervention was compared between SCs group and control group in the 2 different subgroups. The BBB score of SN subgroup was significantly increased in the SCs group than the control group at 4 weeks after SCs transplantation (WMD $=1.57 ; 95 \%$ CI: $0.74-2.41 ; \mathrm{P}=0.0002)$.The heterogeneity was high $\left(\mathrm{I}^{2}=95 \%\right)$. Significance was also found between SCs group and the control group in the BBB score of the DB subgroup (WMD = 3.04; 95\% CI: 1.59-4.49; P < 0.00001). The heterogeneity was high $\left(I^{2}=80 \%\right)$. The overall BBB score was significantly increased in the SCs group than 


\section{Cellular Physiology \\ Cell Physiol Biochem 2015;37:2171-2182 and Biochemistry \\ Yang et al.: Schwann Cells Transplantation in Spinal Cord Injury}

Fig. 7. Publication bias in Begg's test: Funnel plot of the differences in BBB score means against their precision (inverse standard error).

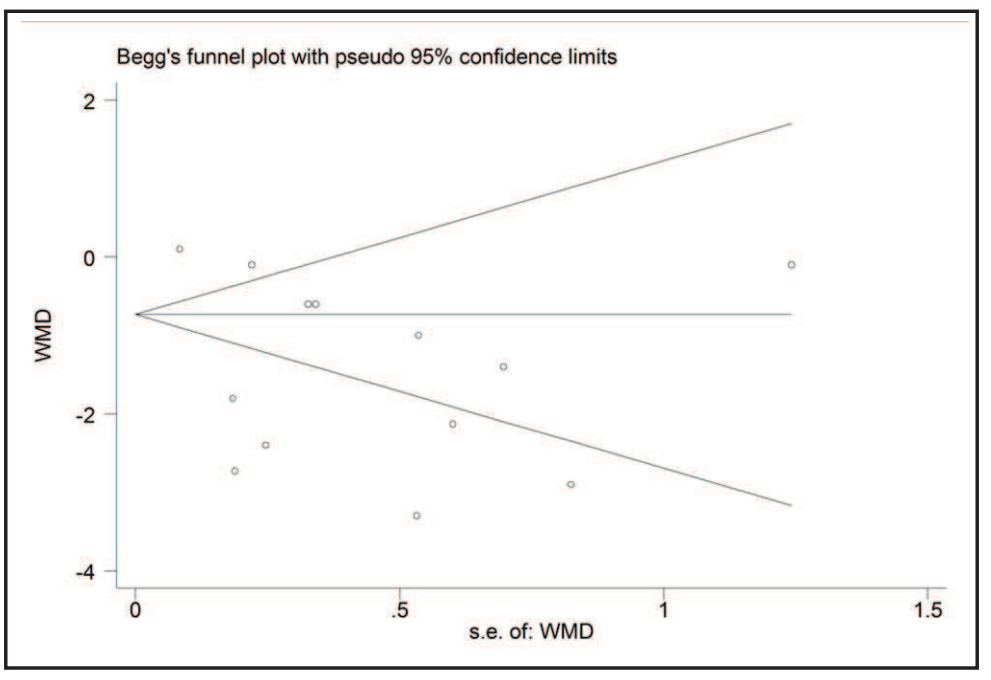

the control group at 4 weeks after SCs transplantation (WMD = 1.84; 95\% CI: 1.03-2.66; P < $0.00001)$. The total heterogeneity was high $\left(\mathrm{I}^{2}=96 \%\right)$. The heterogeneity between subgroups was medium $\left(I^{2}=65.9 \%\right)$ (Fig. 5).

BBB score in subgroups of different ways of SCs transplantation

According to whether scaffolding was used in the process of SCs transplantation, we divided the studies into 2 subgroups (with scaffolding vs. without scaffolding). Given that the same studies were included in the subgroups, we achieved the same results as that in subgroups of different sources of SCs for transplantation. Detailed data were shown in Fig. 6.

\section{Publication bias}

There was no indication of a publication bias either from the result of Egger's test $(\mathrm{P}=$ 0.087) or Begg's test $(P=1.000)$. Visual inspection of the funnel plot was also in agreement with the statistical test, with no apparent asymmetry (Fig. 7).

\section{Discussion}

To date therapies of cell transplantation have been considered as a promising strategy for SCI in both pre-clinical researches and clinical trials $[10,11]$. Schwann cells are one of the most widely used cell types for transplantation to restore the injured spinal cord [1217]. Effects of this therapy may be related to a variety of factors (such as neurotrophin-3, brain-derived neurotrophic factor, nerve growth factor, neurotrophic factor, glial cell linederived neurotrophic factor, and fibroblast growth factor, etc.) expressed by Schwann cells. In addition, Schwann cells secrete substrates such as laminin, fibronectin, and collagen which have been demonstrated to play an important role in promoting the axonal growth both in PNS and central nervous system (CNS) [35, 36]. Although the role of this therapy in repairing the injured spinal cord and improving the locomotor recovery has been evaluated in a number of clinical trials, there was no study to summarize the effects of Schwann cells transplantation. Given this, we conducted this systematic review and meta-analysis to summarize the pre-clinical evidence on the use of Schwann cells transplantation and its potential to improve neurological recovery.

In the present study, we found that SCs transplantation could not significantly improve the locomotor recovery at a short time after intervention (1 week) in both impacted SCI model and hemi-sectioned model. However, in the subgroup of transected model, the pooled data demonstrated that BBB score was significantly increased after treatment of SCs injection at 1 week after intervention. Outcome of BBB score at $3 w$ or $5-7 w$ after 


\section{Cellular Physiology Cell Physiol Biochem 2015;37:2171-2182 and Biochemistry Published online: November 26, 2015 www.karger.com/cpb}

Yang et al.: Schwann Cells Transplantation in Spinal Cord Injury

intervention was significantly improved in SCs group compared with control group in the 3 different SCI models. At over $8 \mathrm{w}$ after intervention, the pooled difference in the BBB score between the two groups also suggested that SCs transplantation has a significant effect in locomotor recovery. Subgroup analysis of different cell count revealed that SCs injection significantly improved the BBB score whether the cell dose was high or low. We also conducted a subgroup analysis based on different sources of SCs. The results showed that BBB score in SCs group was significantly higher than that in the control group regardless of where they were obtained. In addition, we classified the included studies into two subgroups according to whether scaffolding was used in the transplantation process. Coincidently, the same studies were included into the two subgroups as the subgroup of different SCs sources. Due to this, subgroup analysis of with or without scaffolding yielded similar results.

\section{Strengths and Limitations}

To our knowledge, this is the first attempt to summarize the effects of SCs transplantation therapy for SCI. Our up-to-date literature search yielded 13 eligible studies, thus accumulating adequate study power to detect the smallest possible minimal relevant difference in BBB score means. We also assessed study risk of bias using quality components based on empirical evidence. In addition, we addressed the risk of publication bias. Finally, we conducted detailed subgroup analyses based on different categories to reduce the heterogeneity.

Yet despite all this, there are still some limitations in the present study. For instance, in our study, we used BBB score as the comparative outcome between the two groups which subjectively documents limb movements and walking characteristics in an openfield environment. BBB locomotor rating scale has been demonstrated as a useful indicator of the basic overground locomotion of the animals and whether or not the animal would be able to perform more difficult motor-related assessment tests that require specific abilities [20]. Although it was the most widely-used method to assess neurological recovery effects after SCI which was considered validated and reliable, it relies on observation and interpretation and is thus susceptible to bias [37]. Therefore, it should never be used unless the assessors are blinded to the treatment groups. However, among the included references, blinded assessment of BBB score was exactly mentioned in only 5 studies. As is well known, non-blinded outcome assessment often leads to overestimation of intervention effect size in clinical trials, thus increased the risk of bias of this meta-analysis. Additionally, findings and interpretation in systematic reviews are closely related to the experimental design and methodological quality of the included studies. However, to our knowledge, there was no established valid and reliable tool to assess the methodological quality or bias of animal studies, so the methodological quality assessments of each systematic review is not the same $[38,39]$. Besides, low internal validity (systematic bias and random error), publication bias, and low external validity were all major barriers which impeded successful clinical translation of interventional animal studies. Although it is always possible to increase internal validity of a study and properly address publication bias, external validity poses unique challenges which are not easily resolved [40].

\section{Conclusions}

Our systematic review with meta-analyses suggested that SCs transplantation has substantial beneficial effects on locomotor recovery in rat models and promises to be a practical therapy in patients with SCI. The results should, however, be interpreted in light of the known limitations in animal experimental design and methodological quality. 


\section{Cellular Physiology \\ Cell Physiol Biochem 2015;37:2171-2182 \\ \begin{tabular}{l|l}
\hline DOI: $10.1159 / 000438574$ & C 2015 The Author(s). Published by S. Karger AG, Basel
\end{tabular} and Biochemistry Published online: November 26, 2015 www.karger.com/cpb}

Yang et al.: Schwann Cells Transplantation in Spinal Cord Injury

\section{Acknowledgments}

This study was supported by National Natural Foundation of China (NO. 81371968; 81401791; 81371969).

\section{Disclosure Statement}

The authors declare no financial or other conflicts of interest.

\section{References}

1 Devivo MJ: Epidemiology of traumatic spinal cord injury: Trends and future implications. Spinal Cord 2012;50:365-372.

2 Rahimi-Movaghar V, Sayyah MK, Akbari H, Khorramirouz R, Rasouli MR, Moradi-Lakeh M, Shokraneh F, Vaccaro AR: Epidemiology of traumatic spinal cord injury in developing countries: A systematic review. Neuroepidemiology 2013;41:65-85.

3 Silva NA, Sousa N, Reis RL, Salgado AJ: From basics to clinical: A comprehensive review on spinal cord injury. Prog Neurobiol 2014;114:25-57.

4 Chamberlain JD, Meier S, Mader L, von Groote PM, Brinkhof MW: Mortality and longevity after a spinal cord injury: Systematic review and meta-analysis. Neuroepidemiology 2015;44:182-198.

5 Breslin K, Agrawal D: The use of methylprednisolone in acute spinal cord injury: A review of the evidence, controversies, and recommendations. Pediatr Emerg Care 2012;28:1238-1245, 1246-1248.

6 Mattei TA: Surgical decompression after spinal cord injury: The earlier, the better! World Neurosurg 2012;78:384-387.

7 Wyndaele JJ: The impact of early versus late surgical decompression on neurological recovery after traumatic spinal cord injury (SCI). Spinal Cord 2012;50:789.

8 Taylor-Schroeder S, LaBarbera J, McDowell S, Zanca JM, Natale A, Mumma S, Gassaway J, Backus D: The SCIRehab project: Treatment time spent in SCI rehabilitation. Physical therapy treatment time during inpatient spinal cord injury rehabilitation. J Spinal Cord Med 2011;34:149-161.

9 Ruff CA, Wilcox JT, Fehlings MG: Cell-based transplantation strategies to promote plasticity following spinal cord injury. Exp Neurol 2012;235:78-90.

10 Tsuji O, Miura K, Fujiyoshi K, Momoshima S, Nakamura M, Okano H: Cell therapy for spinal cord injury by neural stem/progenitor cells derived from iPS/ES cells. Neurotherapeutics 2011;8:668-676.

11 Sahni V, Kessler JA: Stem cell therapies for spinal cord injury. Nat Rev Neurol 2010;6:363-372.

12 Martin D, Robe P, Franzen R, Delree P, Schoenen J, Stevenaert A, Moonen G: Effects of Schwann cell transplantation in a contusion model of rat spinal cord injury. J Neurosci Res 1996;45:588-597.

13 Golden KL, Pearse DD, Blits B, Garg MS, Oudega M, Wood PM, Bunge MB: Transduced Schwann cells promote axon growth and myelination after spinal cord injury. Exp Neurol 2007;207:203-217.

14 Kamada T, Koda M, Dezawa M, Anahara R, Toyama Y, Yoshinaga K, Hashimoto M, Koshizuka S, Nishio Y, Mannoji C, Okawa A, Yamazaki M: Transplantation of human bone marrow stromal cell-derived Schwann cells reduces cystic cavity and promotes functional recovery after contusion injury of adult rat spinal cord. Neuropathology 2011;31:48-58.

15 Wiliams RR, Bunge MB: Schwann cell transplantation: A repair strategy for spinal cord injury? Prog Brain Res 2012;201:295-312.

16 Guest J, Santamaria AJ, Benavides FD: Clinical translation of autologous Schwann cell transplantation for the treatment of spinal cord injury. Curr Opin Organ Transplant 2013;18:682-689.

17 Zaminy A, Shokrgozar MA, Sadeghi Y, Norouzian M, Heidari MH, Piryaei A: Transplantation of schwann cells differentiated from adipose stem cells improves functional recovery in rat spinal cord injury. Arch Iran Med 2013;16:533-541.

18 Zhang SX, Huang F, Gates M, Holmberg EG: Role of endogenous Schwann cells in tissue repair after spinal cord injury. Neural Regen Res 2013;8:177-185.

19 DerSimonian R, Laird N: Meta-analysis in clinical trials. Control Clin Trials 1986;7:177-188. 


\section{Cellular Physiology Cell Physiol Biochem 2015;37:2171-2182 \begin{tabular}{ll|l} 
DOI: 10.1159/000438574 & $\begin{array}{l}\text { @ 2015 The Author(s). Published by S. Karger AG, Basel } \\
\text { www.karger.com/cpb }\end{array}$ \\
\hline
\end{tabular}}

Yang et al.: Schwann Cells Transplantation in Spinal Cord Injury

20 Basso DM, Beattie MS, Bresnahan JC: Graded histological and locomotor outcomes after spinal cord contusion using the NYU weight-drop device versus transection. Exp Neurol 1996;139:244-256.

21 Scheff SW, Saucier DA, Cain ME: A statistical method for analyzing rating scale data: The BBB locomotor score. J Neurotrauma 2002;19:1251-1260.

22 Zhang SQ, Wu MF, Piao Z, Yao J, Li JH, Wang XG, Liu J: Edaravone combined with Schwann cell transplantation may repair spinal cord injury in rats. Neural Regen Res 2015;10:230-236.

23 Marcol W, Slusarczyk W, Larysz-Brysz M, Francuz T, Jedrzejowska-Szypulka H, Labuzek K, Lewin-Kowalik J: Grafted activated schwann cells support survival of injured rat spinal cord white matter. World Neurosurg 2015;84:511-519.

24 Wang X, Xu XM: Long-term survival, axonal growth-promotion, and myelination of Schwann cells grafted into contused spinal cord in adult rats. Exp Neurol 2014;261:308-319.

25 Kanno H, Pressman Y, Moody A, Berg R, Muir EM, Rogers JH, Ozawa H, Itoi E, Pearse DD, Bunge MB: Combination of engineered Schwann cell grafts to secrete neurotrophin and chondroitinase promotes axonal regeneration and locomotion after spinal cord injury. J Neurosci 2014;34:1838-1855.

26 Zaminy A, Shokrgozar MA, Sadeghi Y, Noroozian M, Heidari MH, Piryaei A: Mesenchymal stem cells as an alternative for Schwann cells in rat spinal cord injury. Iran Biomed J 2013;17:113-122.

27 Hill CE, Brodak DM, Bartlett BM: Dissociated predegenerated peripheral nerve transplants for spinal cord injury repair: A comprehensive assessment of their effects on regeneration and functional recovery compared to Schwann cell transplants. J Neurotrauma 2012;29:2226-2243.

28 Wang H, Liu C, Ma X: Alginic acid sodium hydrogel co-transplantation with Schwann cells for rat spinal cord repair. Arch Med Sci 2012;8:563-568.

29 Li BC, Xu C, Zhang JY, Li Y, Duan ZX: Differing Schwann cells and olfactory ensheathing cells behaviors, from interacting with astrocyte, produce similar improvements in contused rat spinal cord's motor function. J Mol Neurosci 2012;48:35-44.

30 Pourheydar B, Joghataei MT, Bakhtiari M, Mehdizadeh M, Yekta Z, Najafzadeh N: Co- transplantation of bone marrow stromal cells with schwann cells evokes mechanical allodynia in the contusion model of spinal cord injury in rats. Cell J 2012;13:213-222.

31 Kamada T, Koda M, Dezawa M, Anahara R, Toyama Y, Yoshinaga K, Hashimoto M, Koshizuka S, Nishio Y, Mannoji C, Okawa A, Yamazaki M: Transplantation of human bone marrow stromal cell-derived Schwann cells reduces cystic cavity and promotes functional recovery after contusion injury of adult rat spinal cord. Neuropathology 2011;31:48-58.

32 Sharp KG, Flanagan LA, Yee KM, Steward O: A re-assessment of a combinatorial treatment involving Schwann cell transplants and elevation of cyclic AMP on recovery of motor function following thoracic spinal cord injury in rats. Exp Neurol 2012;233:625-644.

33 Someya Y, Koda M, Dezawa M, Kadota T, Hashimoto M, Kamada T, Nishio Y, Kadota R, Mannoji C, Miyashita T, Okawa A, Yoshinaga K, Yamazaki M: Reduction of cystic cavity, promotion of axonal regeneration and sparing, and functional recovery with transplanted bone marrow stromal cell-derived Schwann cells after contusion injury to the adult rat spinal cord. J Neurosurg Spine 2008;9:600-610.

34 Zhang X, Zeng Y, Zhang W, Wang J, Wu J, Li J: Co-transplantation of neural stem cells and NT-3overexpressing Schwann cells in transected spinal cord. J Neurotrauma 2007;24:1863-1877.

35 Takami T, Oudega M, Bates ML, Wood PM, Kleitman N, Bunge MB: Schwann cell but not olfactory ensheathing glia transplants improve hindlimb locomotor performance in the moderately contused adult rat thoracic spinal cord. J Neurosci 2002;22:6670-6681.

36 Oudega M, Xu XM: Schwann cell transplantation for repair of the adult spinal cord. J Neurotrauma 2006;23:453-467.

37 Hrobjartsson A, Thomsen AS, Emanuelsson F, Tendal B, Hilden J, Boutron I, Ravaud P, Brorson S: Observer bias in randomized clinical trials with measurement scale outcomes: A systematic review of trials with both blinded and nonblinded assessors. CMAJ 2013;185:E201-E211.

38 Mignini LE, Khan KS: Methodological quality of systematic reviews of animal studies: A survey of reviews of basic research. BMC Med Res Methodol 2006;6:10.

39 Faggion CJ, Listl S, Giannakopoulos NN: The methodological quality of systematic reviews of animal studies in dentistry. Vet J 2012;192:140-147.

40 Akhtar AZ, Pippin JJ, Sandusky CB: Animal models in spinal cord injury: A review. Rev Neurosci 2008;19:4760. 